\title{
Exploring Engineering-Educators' Perceptions and Challenges on the IR 4.0 at a Technical University in Malaysia
}

\author{
Ridzuan Md Sham ${ }^{1}$, Zizah Che Senik ${ }^{2}$, Muhammad Alief Danial ${ }^{3}$ \\ ${ }^{1}$ Industrial Automation, Universiti Kuala Lumpur MFI, Malaysia, ridzuan@unikl.edu.my \\ ${ }^{2}$ Faculty of Economics and Management, Universiti Kebangsaan Malaysia, Malaysia, zizahcs@ukm.edu.my \\ ${ }^{3}$ Industrial Automation, Universiti Kuala Lumpur MFI, Malaysia, danialhanafiah @ gmail.com
}

\begin{abstract}
This paper presents empirical findings on engineering-educators' perceptions and challenges on the Fourth Industrial Revolution (IR 4.0) at a technical university in Malaysia. Engineering education plays essential roles in ensuring successful accomplishment of the IR 4.0. Despite awareness of the importance of IR 4.0, previous research has not yet specifically focused on the IR 4.0 related to engineering education. Using a quantitative approach, insights from the engineering-educators were gathered to explore their perception on and challenges of the IR4.0 at their institution. With that aim, a set of self-developed questionnaire was used via Google Form to collect data at one technical university in Malaysia. 146 engineering-educators responded in the study. The findings highlighted that more than $80 \%$ of engineering-educators have extensive level of understanding on the IR 4.0, and 95\% emphasized the importance of inclusion IR 4.0 elements in bachelor degree curriculums. The study discovered two main challenges to implement IR 4.0 at the university which are financial limitation and lack of expertise to execute the IR 4.0. This explorative study highlights important implications to the practice of engineering education in the era IR 4.0 in Malaysia. In preparing the nation toward IR 4.0, the Ministry of Higher Education of Malaysia needs to rethink on education designs and curriculums to diminish the threats imposed by IR 4.0 implementation. In general, the government should create public awareness on the readiness and preparedness of IR 4.0 particularly in the education industry. For future research, more rigorous study using larger sample should be conducted. In addition, research should apply qualitative methodology to gain in-depth feedback on the IR 4.0.
\end{abstract}

Key words: Industrial Revolution 4.0 (IR4.0); Engineering Technology Education; Engineering-educators.

\section{INTRODUCTION}

The world today stands on the brink of technology and industrial revolutions that gives tremendous effect to our life. The Industrial Revolution (IR) that has started at the end of the 18th century has proved itself to be a backbone of the country's economy, growth and development. Since then, there have been four industrial revolutions: Industry 1.0 (in the year 1784) - the invention of first steam engine; Industry 2.0 (in the year of 1870) - the first time moving belt conveyor was used to drive through electrical power; Industry 3.0 (In the mid of 1970s) - Electronics \& Information Technology began to expand rapidly into industries; and Industry 4.0 (in the of 2000s) - based on the use of Automation and data exchange in manufacturing technologies [1].

Industrial Revolution 4.0 (IR 4.0) is a "term for the digital revolution in industrial production emerging from the comprehensive networking and computerisation of all areas of production" [2: p.4]. [3] stated that the aim of IR 4.0 is to connect all production resources to empower their interaction in real time with the help of Information and Communications Technologies (ICT). The IR 4.0 is expected to affect the whole world in all aspects. The topic of IR 4.0 has been initially addressed almost exclusively from a technological perspective to educational viewpoint. Technologies impact people hugely, and the IR 4.0 wave requires a significant change in workforce skills, organizational structures, leadership mechanisms and corporate culture.

According to [4], in managing the digital transformation, education industry especially Engineering Education is an important field of knowledge in preparing for the IR 4.0 Era. The new era will create many new cross-functional roles for which knowledge on IT and production cannot be separated. This indicates that the universities and their engineering departments have a vital role in fulfilling the need of IR 4.0.

In relation to the IR 4.0, "Education 4.0" was introduced, which aligns man and machine to enable new possibilities, harnesses the potential of digital technologies, personalized data, open sourced content, and the new humanity of this globally-connected, technology-fueled world, and establish a blueprint for the future of learning [5][14]. Education 4.0 is needed in order to prepare future graduates for work [14][23].

With no exception, Malaysia needs to respond to the requirements of IR4.0 in the future of education in the country [1][6][23]. Thus, this paper argues that for universities to continue to produce successful graduates, Education 4.0 that embeds IR 4.0 must be implemented at tertiary education level. For instance, in engineering education, the IR 4.0 
emphasizes on three groups: educational content, educational technologies, and working in interdisciplinary teams [4], indicating that the education requirements, curriculum designs, as well as skill and knowledge need to be redefined in order to incorporate with the IR 4.0. This means the teaching and learning must suit with the current wave of IR 4.0. Therefore, with an unpredictable pace and ways of the IR4.0, engineering education should prepare to face the era by providing new curriculum designs of engineering education [14].

With no doubt engineering education play essential roles in ensuring successful accomplishment of the IR 4.0 in Malaysia. Despite awareness of the importance of IR 4.0 across the nation, previous research has not yet specifically focused on the IR 4.0 related to engineering education. Realizing the importance of understanding the IR4.0, this study attempts to explore the perception of engineeringeducators on the IR 4.0 at a technical university in Malaysia. In addition, the study will identify the potential challenges of IR 4.0 faced by the technical university. This study will strengthen the understanding of the IR4.0, especially in the engineering education. It provides several vital implications to policymakers, academics, and researchers.

The remainder of this paper is organized as follows. Section 2 reviews the literature. Section 3 describes the research methodology. Section 4 presents the findings. Section 5 deliberates on the discussions and implications. Finally, Section 6 provides the conclusion of the study.

\section{LITERATURE REVIEW}

Over the past few years, the term Industrial Revolution 4.0 (IR 4.0) has attracted more studies all over the world [24][25]. Recently, there have been several studies in the literature that reports about the IR 4.0 in various industries. According to [25] the manufacturing industries are the main research areas of the IR 4.0, in which papers are mainly related to Engineering and Computer Science fields. It has been noted that the IR 4.0 is characterized by a fusion of technologies [7] affecting the way human live, work, play, socialize and even on how human should behave [8] that will bring huge impact to the worldwide including education industry. However, up to 2017 , the literature review does not show much empirical evidence on the IR 4.0 and education industry [25].

Education is dynamic since it evolves more often than societies realize. With multifaceted digital technologies today, higher learning institutions particularly engineering education are faced with the demands and needs of the students. Technical universities and academics are challenged with the ideas on implementing IR4.0 in their curriculum designs and teaching approaches [9][10], so that students are equipped with necessary skills and expertise to be ready for the IR 4.0. The engineering academic context needs to blend both hard skills (such as, strong understanding of industry standards, and comfort working with computers) and soft skills (such as strong analytical thinking, communication skills, teamwork and leadership skills) as well as digital skills that would be useful with the advent of IR 4.0 [26].

Researchers have shown interest debating on the IR 4.0 and Engineering Education, among others, such as [2] [12] [13] [14]. For example, [2][20] focus on the changing role of engineering education in the IR 4.0 era and suggesting that in preparing for the IR 4.0 wave, technical tertiary or university should pay attention to three issues namely, educational content, educational technologies, and working in interdisciplinary teams. This suggests that the curriculum designs, the educators' mind-sets and their teaching approach must integrate the engineering programs with the needs of IR 4.0.

Malaysia is also now moving toward fulfilling the need of meeting the IR 4.0 through the introduction of Education 4.0 especially at its higher learning institutions [11]. Educators use different ways of teaching, and in the field of engineering education, the usage of technologies in teaching is so much required. Inevitably the exposure towards IR 4.0 is still low since it is quite a recent phenomenon [28]. Some academic researchers [14] proposed an enabling ecosystem for Malaysian higher education 4.0 in facing the IR 4.0 as follows:

Stage 1: Institutional Readiness (Managing Convergences, Fluidity, Powershift, Contigency Capability \& Competency Digital Governance \& Accountability Financial Investment Digital Resilience Social, Cultural \& Ethical).

Stage 2: Integration of Institutional Vertical \& Horizontal Value Chains (Vertical Networking of Smart Institutional Systems Horizontal Integration via a New Generation of Global Value Chain Networks).

Stage 3: Institutional Products and Services Innovations (Curriculum Academic Programs MOOCs Research Professional Development Consultancy Data Services)

All in all, the redesigning of engineering education for instance, in the Mechatronics program, will create many new cross-functional roles for which workers will need both IT and production knowledge [12]. [19] argues that the current courses on design, engineering, and management related to production and manufacturing do not systematically deliver the necessary skills and knowledge for an effective deployment of additive manufacturing technologies, thus there is a need to develop new education and training programs to support the provision of additive manufacturing-skilled designers, engineers, and managers.

Increasing number of interdisciplinary study programs has integrated IT and engineering, thus literature has also discussed on the challenges of IR 4.0 to the academic institutions [14][15][16][17][20][21][22]. Despite the growing body of economic research on IR 4.0, little attention has been paid to examine the challenges that are considered relevant for the implementation of IR 4.0 [17], such as in manufacturing companies [18], what is more in the engineering education aspect. 
The implementation of IR 4.0 through virtual and digital platforms may impose fundamental changes on industrial processes in many nations due to cyber security issues. This concern has created another challenge in the implementation of IR 4.0 [27]. Thus, the engineering education framework such as its curriculum designs, teaching and learning infrastructures need to be realigning with the IR 4.0 and Education 4.0. By doing so, the engineering education can be brought up to another level, and most importantly the technical universities can prepare students to expand their role in ongoing re-qualification of the industrial workforce [20].

\section{RESEARCH AND METHODS}

\section{Research Setting}

The motivation to conduct this study was not only due to the current issue on the IR 4.0 but the nature of the setting of the study as one top technical university in Malaysia (Note: the name of the university will not be revealed. Throughout the paper, it will be known as technical university). Established in the early 2000s, this technical university is based at the heart of Malaysia's capital and commerce area. The university has several institutes and branches throughout Malaysia offering various courses and programs. Wearing a motto of "where knowledge is applied and dreams are realized, the university aims to provide graduates with knowledge, skills and attitude required to contribute towards the nation. To date, the university has produced almost 60,000 graduates. Therefore, the research setting fits the purpose of the study that was to explore engineering-educators' perceptions and challenges on the IR 4.0 at a technical university in Malaysia.

\section{Research Approach}

This study employed an exploratory quantitative approach grounded on two main research questions as follows:

1. What are the perceptions of engineering-educators on the IR 4.0 at this institution of the technical university?

2. What are the potential challenges faced by this institution of the technical university if it wants to implement the IR 4.0?

To be able to answer those research questions, a set of questionnaire was created based on the review of literature. The data were collected through a set of self-developed questionnaire consisted of three sections:

Section A: Respondents' profile (consists of two criteria)

Section B: Perceptions on IR 4.0 (consists of five items)

Section C: Potential Challenges of IR 4.0 (consists of six items)

A purposive sampling was utilized and only engineeringeducators teaching degree level at one selected institution of the technical university recruited as respondents. The questionnaire was distributed to 197 engineering-educators through Google Forms. A total of 146 engineering educators responded to this survey resulting in $74 \%$ of response rate.

The study used a 5-point Likert scale (1: Strongly Disagree (SD); 2: Disagree (D); 3: Neutral (N); 4: Agree (A); and 5: Strongly Agree (SA) in the questionnaires. A few open-ended questions were also included in the questionnaire to gain opinion on how to prepare the university with potential challenges yielded by the IR 4.0.

\section{Respondents' Profile}

As stated earlier, the respondents in this study involved only engineering-educators teaching degree level. Only two criteria were selected which were highest level of academic degree and years of teaching experience. In regard to first criteria, of 146 engineering-educators, majority of them hold Masters Degree (61\%), followed by PhD level (29\%) and Bachelor and professional qualifications (10\%). In regard to the second criteria, more than $50 \%$ of the engineering-educators have 10 to 20 years of teaching experience, about $41 \%$ has less than 10 years, and $8 \%$ of them have more than 20 years of teaching. Table 1 presents the profile of respondents at this technical university.

Table 1: Profile of Respondents

\begin{tabular}{|c|c|c|}
\hline \multicolumn{2}{|c|}{ Selected Characteristics } & \multicolumn{2}{|c|}{$\mathbf{N = 1 4 6}$} \\
\cline { 2 - 3 } & Freq & \% \\
\hline Highest level of academic degree & & \\
$\bullet \quad$ Bachelor and Professional Qualifications & 15 & $10 \%$ \\
$\bullet \quad$ Master & 89 & $61 \%$ \\
$\bullet \quad$ PhD & 43 & $29 \%$ \\
\hline Years of teaching experience & & \\
$\bullet \quad$ Less than 10 years & 74 & $41 \%$ \\
- Between 10 to 20 years & 12 & $51 \%$ \\
- More than 20 years & & \\
\hline
\end{tabular}

Next, the findings of the study will be presented and discussed.

\section{FINDINGS}

In the following, we present the findings based on the two research questions. The descriptive results of the study on the perceptions on IR4.0 and potential challenges on the IR 4.0 perceived by the respondents will be presented accordingly.

\section{Engineering-educators' Perceptions on IR4.0}

The first research question was about the perception of engineering-educators on IR4.0 that contained five items in the questionnaire. Table 2 shows the results on the frequency counts and percentage. To ease the description of the findings on each item of the perception on IR 4.0, the percentage results of the Likert scale will be combined such as, the strongly agree (SA) with agree (A), and the strongly disagree (SD) with disagree (D). 
Table 2: Perceptions on IR 4.0

\begin{tabular}{|c|c|c|c|c|c|}
\hline \multirow[b]{2}{*}{ Perceptions on IR 4.0 } & SD & D & $\mathbf{N}$ & $\mathbf{A}$ & SA \\
\hline & $\begin{array}{c}\text { Frq } \\
\%\end{array}$ & $\begin{array}{c}\text { Frq } \\
\%\end{array}$ & $\begin{array}{c}\text { Frq } \\
\%\end{array}$ & $\begin{array}{c}\text { Frq } \\
\%\end{array}$ & $\begin{array}{c}\text { Frq } \\
\%\end{array}$ \\
\hline 1. Level of understanding on IR 4.0 & $\begin{array}{c}25 \\
17 \%\end{array}$ & $\begin{array}{c}3 \\
2 \%\end{array}$ & - & $\begin{array}{l}100 \\
69 \%\end{array}$ & $\begin{array}{c}18 \\
12 \%\end{array}$ \\
\hline $\begin{array}{l}\text { 2. The importance of inclusion IR } 4.0 \\
\text { elements in a bachelor's degree } \\
\text { curriculum. }\end{array}$ & $\begin{array}{c}8 \\
5 \%\end{array}$ & $\begin{array}{c}0 \\
0 \%\end{array}$ & - & $\begin{array}{c}74 \\
51 \%\end{array}$ & $\begin{array}{c}64 \\
44 \%\end{array}$ \\
\hline $\begin{array}{l}\text { 3. Efforts by institution to include } \\
\text { elements of IR } 4.0 \text { in the bachelor's } \\
\text { degree programme. }\end{array}$ & $\begin{array}{c}37 \\
26 \%\end{array}$ & $\begin{array}{c}3 \\
2 \%\end{array}$ & - & $\begin{array}{c}69 \\
46 \%\end{array}$ & $\begin{array}{c}37 \\
26 \%\end{array}$ \\
\hline $\begin{array}{l}\text { 4. Current bachelor's degree programme } \\
\text { at this technical university prepares } \\
\text { students to work in IR } 4.0 \text {-based } \\
\text { industry. }\end{array}$ & $\begin{array}{c}47 \\
32 \%\end{array}$ & $\begin{array}{l}25 \\
17 \%\end{array}$ & $\begin{array}{c}3 \\
2 \%\end{array}$ & $\begin{array}{c}67 \\
45 \%\end{array}$ & $\begin{array}{c}5 \\
3 \%\end{array}$ \\
\hline $\begin{array}{l}\text { 5. The headquarters of this technical } \\
\text { university has put strong efforts to } \\
\text { include elements of IR } 4.0 \text { in the } \\
\text { bachelor programme. }\end{array}$ & $\begin{array}{c}32 \\
22 \%\end{array}$ & $\begin{array}{c}13 \\
9 \%\end{array}$ & $\begin{array}{c}6 \\
4 \%\end{array}$ & $\begin{array}{c}65 \\
45 \%\end{array}$ & $\begin{array}{c}30 \\
20 \%\end{array}$ \\
\hline
\end{tabular}

In response to Item 1, the level of understanding on IR 4.0, of the total respondents $(\mathrm{N}=146)$, by combining the percentage on strongly agree (SA) and agree (A), we could see from the table that about $81 \%$ have agreed that they have extensive level of understanding on the IR 4.0. Another 19\% of the engineering-educators stated that they obtain little understanding on the issue of IR 4.0.

Item 2 that stated the importance of inclusion IR 4.0 elements in a bachelor's degree curriculum received quite a high response in which 95\% consent that the institution in this technical university emphasizes the importance of inclusion IR 4.0 elements in a bachelor's degree curriculum. Only 5\% of the engineering-educators showed otherwise.

Regarding the efforts by the institution of this technical university to include elements of IR 4.0 in the bachelor's degree programme (Item 3), about $72 \%$ of the engineering-educators gave positive responses, while $28 \%$ of them stated that the institutions has not shown good attempt to provide IR 4.0 aspect in the curriculum.

Item 4 delineates that current bachelor's degree programme at this institution of the technical university prepares students to work in the IR 4.0-based industry. In response to this item, about $48 \%$ stated that current bachelor's degree programme offered at this technical university does prepare students to work in the IR 4.0-based industry, while $49 \%$ stated otherwise, and $3 \%$ of the engineering-educators were neutral about it.

In response to Item 5 which indicates that the headquarters of this technical university has put strong efforts to include elements of IR 4.0 in the bachelor programme, about $65 \%$ of the engineering-educators agreed that the headquarters of this technical university has indeed put strong efforts to include elements of IR 4.0 in the bachelor programme, but $31 \%$ disagreed indicating that this technical university has put little effort to blend the IR 4.0 elements in the curriculum, while $6 \%$ was neutral about it.

To summarize the findings on the perception on IR 4.0, we could highlight that the engineering-educators at this selected institution have highly perceive on the importance of inclusion IR 4.0 elements in a bachelor's degree curriculum due to their extensive level of understanding on the IR 4.0. They also believe that the institution has given strong efforts to include elements of IR 4.0 in the bachelor's degree programme because of the support from the headquarters of this technical university. However, the engineering-educators perceive that they are not really sure the institution has prepared students to work in the IR 4.0-based industry.

\section{Potential Challenges of IR 4.0}

Next, we will address the second research question on the potential challenges faced by this institution of the technical university if it wants to implement the IR 4.0. Six items were provided for the respondents in which they could only tick or select one item to indicate their responses in this section. Table 3 displays the results of the potential challenges of IR4.0 faced by this institution at this technical university.

Table 3: IR4.0 Potential Challenges

\begin{tabular}{|l|c|c|}
\hline IR 4.0 Potential Challenges Faced by the institution & \multicolumn{2}{|c|}{ N=146 } \\
\cline { 2 - 3 } at this technical university & Freq & \% \\
\hline Lack of exposure/awareness on IR 4.0. & 16 & $11 \%$ \\
\hline Lack of expertise/manpower in implementing IR 4.0. & 38 & $26 \%$ \\
\hline $\begin{array}{l}\text { Lack of money to purchase IR 4.0 hardware and } \\
\text { software. }\end{array}$ & 45 & $31 \%$ \\
\hline Lack of encouragement from the management level. & 4 & $3 \%$ \\
\hline Lack of knowledge on IR 4.0. & 18 & $12 \%$ \\
\hline Lecturers are too busy with current tasks. & 25 & $17 \%$ \\
\hline
\end{tabular}

Accordingly, of 146 engineer-educators, $11 \%$ responded that they lack of exposure or awareness on the IR 4.0, while $26 \%$ agreed that the institution has lack of expertise or manpower to implement IR 4.0 at the this technical university. Another challenge that received $31 \%$ responses by the engineer-educators was that the institution and the technical university have lack of money to purchase the hardware and software related to the IR4.0. Four of the 146 engineer-educators $(3 \%)$ perceived that they have lack of encouragement from the management level to pursue the IR 4.0. Meanwhile, $12 \%$ agreed that they have lack of knowledge on IR4.0, and finally 25 of them $(17 \%)$ responded that the lecturers are too busy with current tasks.

Figure 1 displays the results in bar chart that provides a better visualization of the findings.

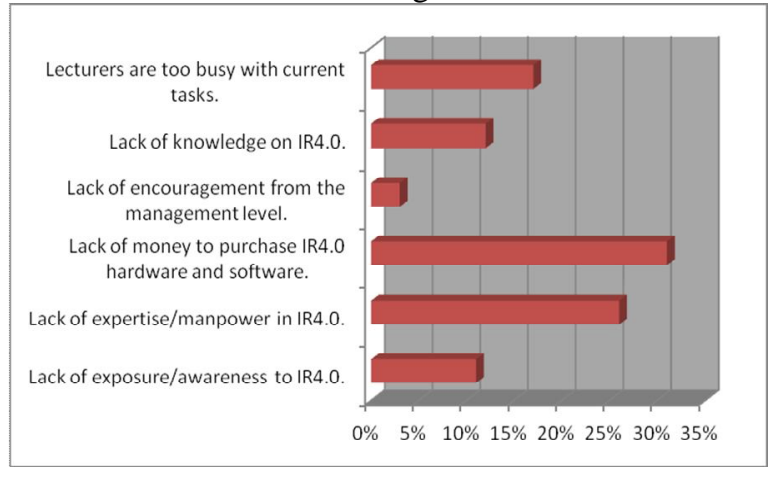

Figure 1: Ranking of the potential challenges of IR4.0 
We then rearranged the feedback on the potential challenges of IR4.0 perceived by engineering-educators at this institution at this technical university based on the highest to the lowest percentage of responses. In brief Figure 1 reveals the ranking of the challenges of implementing the IR 4.0 at this particular technical university accordingly as follow:

1. Lack of money to purchase IR 4.0 hardware and software (31\%),

2. Lack of expertise or manpower in IR 4.0 at this technical university (26\%),

3. Lecturers are too busy with current tasks (17\%),

4. Lack of knowledge on IR 4.0 (12\%),

5. Lack of exposure or awareness on IR 4.0 (11\%), and

6. Lack of encouragement from the management level $(3 \%)$.

To summarize the findings on the potential challenges of the IR 4.0, we could see that financial constraint is the main challenge for the institution of this technical university to implement the IR 4.0 elements. In order to implement the IR 4.0, expertise of manpower is an issue in this institution because the academics are tied with current tasks and routine, resulting in having little knowledge on the IR 4.0. Finally, the academics (engineer-educators) are not being given exposure or awareness on the IR 4.0 and encouragement from the management level.

This section has presented the results that addressed the two research questions of the study.

\section{DISCUSSION}

This paper presents empirical findings on engineering-educators' perceptions and challenges on the IR 4.0 at one institution at a technical university in Malaysia. The findings gathered from 146 engineering-educators revealed majority of them have extensive level of understanding on the IR 4.0, and it is important for the technical tertiary or university to embrace IR 4.0 elements in their bachelor's degree curriculum. The findings go in line with previous literature [8][9][10][13][15] that engineering education should revisit their academic designs to fit with the wave of IR 4.0. In general, this indicates that education industry in Malaysia needs to embed the element of IR 4.0 more so that students are more exposed and aware of the IR 4.0.

Although efforts to embed the curriculum with IR 4.0 element have been observed by the engineering-educators as well as the technical university, it is still far reaching the demand of the future particularly in the workforce environment. This finding fits well with the earlier finding by [19] who argued that the current courses engineering education must be able to support the demand and skills needed in the all sectors. In preparing the nation toward the IR 4.0, again, as suggested by [28] the policy makers especially under the Ministry of Higher Education of
Malaysia needs to provide training for academics to align teaching and learning to suit with the current wave of IR 4.0.

Meanwhile, the study also discovered that lack of money to purchase IR4.0 hardware and software is the main challenges of implementing IR4.0. This conform to the findings [9][10] that financial limitation is the main constraint in implementing the IR 4.0. This is a very important aspect that majority of technical tertiary institutions or universities in Malaysia are having financial predicament to realize the demand of IR 4.0 in their institutions. Besides that, due to lack of knowledge on IR4.0 among the educators and management, the technical university has lack of expertise or manpower to devise or design the curriculum to fit the demand of IR 4.0.

Consequently, the findings of this study in regards to the perception and challenges of IR 4.0 in the engineering education concur with suggestions from [14] that the nation needs to prepare an enabling ecosystem for Malaysian higher education 4.0 in facing the IR 4.0. We need to make sure that the institutions are ready to blend the IR 4.0 in the system by integrating value chains vertical and horizontal which in turn enable the institution to pursue innovation on products and services.

In line with the discussion regarding the perception of engineering educators on IR 4.0 and challenges to implement it in the technical university, the policy makers such as the Ministry of Higher Education of Malaysia needs to rethinking on the designs, framework and curriculum in education industry for that our nation could diminish the threats impose by IR 4.0 implementation.

\section{CONCLUSION}

The objective of the research is to explore the engineer-educators' perceptions and challenges on the IR 4.0 at a technical university in Malaysia. The study utilized a Google Form survey through quantitative approach based on a set of self-developed questionnaire guided by two research questions.

The overall findings show that this study has contributed to enhance the knowledge on IR 4.0 particularly in regard to the engineering education. This small scale study has no doubt contributes to empirical findings on the perception on and challenges of the implementation of IR 4.0.

Naturally, our investigation is subject to several limitations that must be taken into consideration. The empirical findings were only limited to one particular institutions at a technical university in Malaysia, which can be extended with the composition of few technical universities or universities that offer engineering education programs in Malaysia with greater sample size. The methodology in this study used a survey via Google form presented through descriptive analysis. Other future studies could use more advanced quantitative methodology, and also use more in-depth approach through qualitative methodology. 


\section{REFERENCES}

1. Tilak, G. and Singh, D. Industry 4.0 - 4th Rising Industrial Revolution in Manufacturing Industries and its Impact on Employability and Existing Education System, Pramana Research Journal, vol. 8, no. 11, pp. 161-169, 2018.

2. Schröder, C. The Challenges of Industry 4.0 for Small and Medium-sized Enterprises. Friedrich-Ebert-Stiftung, Germany, p. 4, 2017.

3. Latif, K., Abdul Kadir, A. Z., and Yusof, Y. The Importance of STEP-NC in the IR 4.0 Manufacturing Systems, International Journal of Advanced Trends in Computer Science and Engineering, vol.8, no. 4, pp. 1568 $-2019$.

https://doi.org/10.30534/ijatcse/2019/80842019

4. Cevik, S., Ustundag, A., Kadaifci, C., and Oztaysi, B. The Changing Role of Engineering Education in Industry 4.0 Era (in Industry 4.0: Managing the Digital Transformation), Springer Series in Advanced Manufacturing, pp. 137-151, 2018.

5. Fisk, P. Education 4.0. Retrieved on 22 October 2019 from

http://www.thegeniusworks.com/2017/01/future-educatio n-youngeveryone-taught-togetherl. 2017.

6. Jeshke, S. Retrieved from: http://www.ima-zlw-ifu.rwth-aachen.de/fileadmin/user_u pload/ Retrieved on 22 October 2019 from INSTITUTSCLUSTER/Publikation_Medien/Vortraege/do wnload//EngEducationInd4.0, 2015.

7. Schwab, K. The Fourth Industrial Revolution: What It Means and How to Respond. World Economic Forum. Retrieved from https://www.weforum.org/agenda/2016/01/the-fourth-ind ustrial-revolution-what-it-means-and-how-to-respond/, 2016.

8. Abu Ahmad, I. Is it the dawn of Industrial Revolution 4.0 in Malaysia? My Foresight Magazine. 04, pp.04-07, 2016.

9. Juhary, J. IR4.0 Ready and Aware Academics at the National Defence University of Malaysia, in Redesigning Higher Education Initiatives for Industry 4.0. pp. 284-303, 2019.

https://doi.org/10.4018/978-1-5225-7832-1.ch017

10. Kolandan, S. Industry Revolution 4.0 and Education System in Malaysia. Are we ready for challenges? in Redesigning Higher Education Initiatives for Industry 4.0 pp. 252-264. 2019.

11.Fauzi Othman. (2016). Industry 4.0: A review on industrial automation and robotic. Centre for Artificial Intelligence and Robotic, Universiti Teknologi Malaysia, Kuala Lumpur, Malaysia

12. Huba. M. and Kozak, S. From E-Learning to Industry 4.0, International Conference on Emerging e-Learning Technologies and Applications. Slovakia, p. 1-6, 2016.

13. Wanyama, T.; Singh, I. and Centea, D. A Practical Approach to Teaching Industry 4.0 Technologies. 14th
International Conference on Remote Engineering and Virtual Instrumentation. New York, vol. 22, 2017. https://doi.org/10.1007/978-3-319-64352-6_74

14.Selamat, A., Alias, R. A., Hikmi, S. N., Puteh, M., and Tapsir, S. H. Higher Education 4.0: Current Status and Readiness in Meeting the Fourth Industrial Revolution Challenges. Ministry of Higher Education Malaysia, pp. 23-24, 2017.

15. Bernama.. TVET system vital to meet needs of Industry 4.0. Retrieved July 10, 2019 from http://www.bernama.com. January 12, 2018.

16. Mohd Suud, M. Higher TVET: Meeting future industry and student expectations. Okinawa Jichikaikan, Japan, 2017.

17. Müller, J. M., Kiel, D., \& Kai-Ingo, V.. What drives the implementation of industry 4.0? The role of opportunities and challenges in the context of sustainability. Sustainability, vol. 10, no. 247, pp. 1-24, 2018.

https://doi.org/10.3390/su10010247

18. Wee, D., Kelly, R., Cattel, J. and Breunig, M.. Industry 4.0-How to Navigate Digitization of the Manufacturing Sector; McKinsey \& Company: Dusseldorf, Germany; Berlin, Germany; Munich, Germany, 2015.

19. Despeisse, M. and Minshall, T. Skills and Education for Additive Manufacturing: A Review of Emerging Issues. IFIP International Conference on Advances in Production Management System, Hamburg, Germany, pp. 1-8, 2017.

20. Richert, A., Shehadah, M., Willicks, F. and Jeschke, S. Digital Transformation of Engineering Education Empirical Insights from Virtual Worlds and Human-Robot-Collaboration, International Journal of Engineering Pedagogy. iJEP, vol. 6, nov. 4, pp.23-29, 2016.

21. Thames, J. L., and Schaefer, D. Industry 4.0: an overview of key benefits, technologies, and challenges. In: Thames, L, Schaefer D (eds) Cybersecurity for Industry 4.0.1. Springer (Springer Series in Advanced Manufacturing), Berlin, pp 1-33, 2017.

22. Requirements for Education and Qualification of People in Industry 4.0. Retrieved on 27 December 2019 at

https://www.sciencedirect.com/science/article/pii/S23519 78917305747?via\%3Dihub, 2017.

23.James, F. Everything You Need to Know About Education 4.0, Retrieved on 28 December 2019 via https://www.qs.com/everything-you-need-to-know-educat ion-40/, 2019.

24.Drath, R. and Horch, A. Industrie 4.0: Hit or Hype? IEEE Industrial Electronics Magazine, vol. 8, no. 2, pp. 56-58, 2014.

https://doi.org/10.1109/MIE.2014.2312079

25.Liao, Y., Deschamps, F., Loures, E. D. F. R., and Ramos, L. F. P. Past, Present and Future of Industry 4.0 - a Systematic Literature Review and Research Agenda 
Proposal, International Journal of Production Research vol. 55, no. 12, pp. 3609-3629, 2017.

26. Motyla, B., Baroniob, G', Ubertib, S., Speranzac D., and Filippia, S. How will change the future engineers' skills in the Industry 4.0 framework? A questionnaire survey, Procedia Manufacturing, vol. 11, pp. 1501 1509, 2017.

27. Mohamed Mizan, N. S., Ma'arif, M. Y., Mohd Satar, N. S., and Shahar, S. M. CNDS-Cybersecurity: Issues and Challenges in ASEAN Countries, International Journal of Advanced Trends in Computer Science and Engineering, vol. 8, no. 14, pp. 113 - 119, 2019. https://doi.org/10.30534/ijatcse/2019/1781.42019

28. Azmi, A., Che Ahmad, N. H., Kayat, K., Abdullah, D., and Zubir, H. A. Industry 4.0: Teaching Preferences, Perceptions, and Challenges among Tourism and Hospitality Academicians, International Journal of academic Research in Business \& Social Sciences, vol. 8, no. 15, pp. 351- 365, 2018. 